4. Aleksandrov V. I. Kanenkov V. V. pressure Losses and critical speed according to the results of experiments at the Kachkanarsky GOK. - Mining machinery and electrical engineering. No. 6, 2006. - Pp. 32-37.

5. Baranov Yu. D., Blus B. A., Semenenko E. V., Shurygin V. D. Justification of parameters and modes of operation of hydraulic transport systems of mining enterprises - Institute of geotechnical mechanics named after N. S. Polyakov, Dnepropetrovsk, 2006-416 p.

6. Ivanova T. D. Research and improvement of ground pumps pumping ore tailings of processing plants (on the example of the Magnitogorsk metallurgical combine) - Dissertation for the degree of candidate of technical Sciences-L., 1981. - 28 p.

7. Zavertkin P. S. Increasing the resource of ground pumps by reducing the intensity of water-jet wear of their elements in the systems of hydraulic transport of enrichment tailings-Thesis for the degree of candidate of technical Sciences-Saint Petersburg, 2009. - $115 \mathrm{p}$.

8. Zaripov A. Kh. Assessment of energy efficiency of water drainage installations and compressed air supply systems / / Izv.vuzov. Gorny Zhurnal, 2010, no. 4, Pp. 74-77.

9. Zotov B. N. Program for calculating the expected energy characteristics of center-run pumps / / ECOPUMP-RUS. Moscow. 2016. Pp. 15-19.

10. Menshikov S. S. Improving the efficiency of operation of ground pumps in conditions of water-jet wear-Dissertation for the degree of candidate of technical Sciences-Saint Petersburg, 2014. - 148 p.

11. CFD - BladeGen, Version 3.2 (2000). Users's Guide, AEA Technology Engineering Software Inc.

12. CFX - TurboGrid, Version 1.5 (2000). Software Documentation, User Manual, AEA Technology Engineering Software, Ltd.

13. Nowack O. (2000). Private Communication, Ritz Pumpen GmbH \& Co. KG, Schwabisch Gmund.

\title{
INVESTIGATION OF LEAKAGE CURRENT DISTRIBUTION IN ELECTRICAL WIRING THAT FEEDS A GROUP OF ELECTRIC RECEIVERS WITH A MOTOR LOAD
}

\author{
Balashov O.P. \\ candidate of technical Sciences, \\ associate Professor of the Department of electric power engineering, \\ Rubtsovsky industrial Institute of AltSTU
}

\section{ИССЛЕДОВАНИЕ РАСПРЕДЕЛЕНИЯ ТОКА УТЕЧКИ В ЭЛЕКТРОПРОВОДКАХ, ПИТАЮЩИХ ГРУППУ ЭЛЕКТРОПРИЕМНИКОВ С ДВИГАТЕЛЬНОЙ НАГРУЗКОЙ}

\section{SUMMARY}

Балашов Олег Петрович кандидат технических наук, дочент кафедры электроэнергетики, Рубиовский индустриальный институт АлтГТУ DOI: 10.31618/ESU.2413-9335.2020.1.76.893

The article investigates the distribution of leakage current in low voltage wiring. The regression equation is obtained, which makes it possible to accurately predict the value of the leakage current of the electrical wiring supplying a group of power receivers with motor load.

\section{АННОТАЦИЯ}

В статье исследовано распределение тока утечки в электропроводках низкого напряжения. Получено уравнение регрессии, позволяющее точно спрогнозировать значение тока утечки электропроводок, питающих группу электроприемников с двигательной нагрузкой.

Key words: leakage current, analytical dependence, low voltage wiring.

Ключевые слова: ток утечки, аналитическая зависимость, электропроводка низкого напряжения.

Длительная эксплуатация электропроводок низкого напряжения на объектах социальной инфраструктуры села является одной из причин предаварийного состояния электроустановок, приводящих, в том числе к их возгоранию. В большинстве случаев возникновение такого состояния электропроводок обусловлено токами утечки через изоляцию. На величину токов утечки помимо длительного использования электропроводок влияют: перегрузки, возникающие в ходе эксплуатации и превышающие допустимые значения токовой нагрузки в среднем в $2 \ldots 3$ раза; аварийные режимы, связанные с токами короткого замыкания, хотя они носят кратковременный характер, но обусловлены значительной кратностью. А так же нельзя забывать о влиянии внешних факторов на изоляцию электропроводок и электрооборудования: температуры, влажности, давления, механических воздействий в результате различных динамических усилий.

Для обеспечения защиты от возгорания электропроводок действующими ГОСТами $[1,2]$ в настоящее время и ПУЭ [3] рекомендует применение в электроустановках зданий устройств защитного отключения (УЗО). Их установка способствует созданию высокоэффективных средств электрической защиты, при условии согласовании их уставок $\mathrm{c}$ током утечки в электропроводках. Но при этом следует учитывать, 
что если уставка срабатывания УЗО будет выбрана меньше тока утечки электрической сети, то это вызовет ложные отключения, влияющие на питание потребителей, обеспечивая снижение надежности электроснабжения. Если уставка срабатывания УЗО значительно превысит ток утечки, то это приведет к снижению чувствительности защиты, что ухудшит значительно её эффективность.

Впервые исследования токов утечки в электрических сетях были проведены О.К. Никольским [4]. Им также была разработана специальная методика их измерения. В дальнейшем В.Ф. Королем [5] и Т.В. Ереминой [6] были проведены аналогичные исследования для различных объектов, в том числе сельского хозяйства и быта. Целью этих исследований явилось обоснование технических требований для выбора уставок аппаратов УЗО. Однако, необходимо отметить, что экспериментальные исследования уровней токов утечки в электроустановках объектов социальной инфраструктуры села ранее не проводились. Это было обусловлено, во-первых хорошим состоянием электропроводок и во-вторых действующими нормативными документами того времени, которые не требовали обязательной установки УЗО, но и не носили даже рекомендательный характер.

Актуальность получения данных по распределению токов утечки в электропроводках объектов социальной инфраструктуры села вытекает из следующих позиций: значительного ужесточения требований к электроустановкам таких объектов в плане электро- и пожаробезопасности с одной стороны и современным неудовлетворительным состоянием электропроводок, продолжительность эксплуатации которых составляет 25...30 лет с другой. Кроме того, полученные экспериментальные данные статистических распределений токов утечки в электропроводках зданий позволит исследовать влияние некоторых электрических параметров на его значение и обосновать рациональный выбор уставок аппаратов УЗО в современных условиях.

На основании этого для получения необходимой информации при минимальных затратах воспользуемся методом планирования эксперимента и математической статистики при обработке полученных данных [7]. Основным здесь является определение минимального количества необходимых измерений исследуемого параметра и статистическая проверка гипотезы о законе распределения случайной величины.

В ходе визуального обследования состояния электропроводок, рассматриваемых объектов, и анализа их функционирования были определены факторы, влияющие на величину тока утечки, которыми являются: тип объекта, характеристики электропроводки (длина, сечение, вид изоляции) и вид электрической нагрузки, мощность и количество подключенных электроприемников.
Проведенные мероприятия показали, что наибольшему старению подвержены электропроводки, питающие группу электроприемников с двигательной нагрузкой, поэтому экспериментальные исследования были посвящены получению аналитических зависимостей именно для этих электроустановок.

Для устранения влияния внешних факторов, способствующих значительной погрешности, измерения проводились специализированным цифровым измерительным комплексом АТК-1001 с учетом разделения PEN проводника на отдельные $\mathrm{N}$ и $\mathrm{PE}$ проводники. Методика измерения подробно приведена в [8].

При обработке экспериментальных данных были приняты следующие допущения:

1) электропроводка рассматривалась как цепь с распределенными параметрами;

2) изоляция электропроводок выполнена из поливинилхлорида.

На основании, полученных данных, была построена аналитическая зависимость тока утечки от ряда параметров.

Теснота и форма связи между исследуемой величиной (током утечки) и совокупностью влияющих на нее факторов (мощность электроприемников, количества, параметров электропроводки) устанавливалась на основе математической модели состояния электрической изоляции - уравнения регрессии.

В ходе обработки статистических данных, собранных при экспериментальном исследовании, была доказано, что распределение исследуемой величины близко к нормальному закону, а на основании корреляционного анализа была установлена связь величины тока утечки и числа включенных в сеть электроприемников $\left(K_{\mathrm{n}}=0,79\right)$, их мощностью $\left(K_{\mathrm{P}}=0,71\right)$, а так же протяженностью электрических линий $\left(K_{\ell}=0,24\right)$, попадающих в зону защиты УЗО.

Тогда с учетом принятого допущения о линейности математической модели и представления схемы замещения электропроводок как цепи с распределенными параметрами уравнение регрессии приняло вид:

$$
I_{\mathrm{yT}}=-23,91+0,874 \mathrm{P}+0,79 n+0,097 \ell[\mathrm{MA}]
$$

где $\mathrm{P}$ - установленная мощность группы электроприемников, кВт;

$\mathrm{n}$ - количество, подключенных к линии электроприемников;

$\ell$ - длина электропроводки, м.

Полученное уравнение позволяет достаточно точно прогнозировать ожидаемый ток утечки электропроводки, питающей двигательную группу электроприемников, что подтверждается высокими значениями множественного коэффициента детерминации $(0,928)$ и множественного коэффициента корреляции $(0,964)$.

Проведенный анализ уравнения на адекватность показал, что оно достаточно точно 
описывает установленные закономерности и представляет собой математическую модель состояния изоляции электроустановок на объекте, с помощью которого становится возможным диагностировать величину тока утечки в линии в зависимости от изменения любого из факторов.

ВЫВОДЫ:

Проведенные исследования распределения тока утечки в электропроводках, питающих группу электроприемников $\mathrm{c}$ двигательной нагрузкой позволил: во-первых, выявить основные электрические величины, влияющие на величину тока утечки; во-вторых, получить аналитическую зависимость, позволяющую описать изменение тока утечки от различных параметров и в-третьих, в практическом плане обосновать выбор уставок аппаратов УЗО для повышения уровня пожаробезопасности на объектах социальной инфраструктуры села.

\section{Список литературы:}

1. ГОСТ Р 50571.3 - 94 (МЭК 364-4-41-92). Электроустановки зданий. Часть 4. Требования по обеспечению безопасности. Защита от поражения электрическим током. - Введ. 1995-01-01. - М.: Госстандарт России: Изд-во стандартов, 1995.

2. ГОСТ Р 50669 - 94. Электроснабжение и электробезопасность мобильных (инвентарных) зданий из металла или с металлическим каркасом для уличной торговли и бытового обслуживания населения. - Введ. 1995-01-01. - М.: Госстандарт России: Изд-во стандартов, 1994.
3. Правила устройства электроустановок. 7-е издание. (Гл. 1.1, 1.2, 1.7, 1.9, 7.5, 7.6, 7.10):утв. Мвом энергетики Рос. Федерации 08.07.02: ввод. в действие с 01.01.03. - СПб.: Деан, 2003. 176 с.

4. Никольский, О.К. Защитное отключение на фермах крупного рогатого скота и в жилых домах сельской местности: Автореф. дисс. на соиск. учен. степ. канд. техн. наук/ Никольский Олег Константинович. - М. 1969. - 31 с.

5. Король, В.Ф. Исследование систем обеспечения электробезопасности мобильных электрифицированных машин с кабельным питанием на животноводческих фермах Южной зоны СССР: Автореф. дисс. на соиск. учен. степ. канд. техн. наук/ В.Ф. Король. - М. 1973. - 30 с.
6.
Еремина,
T.B.
Повышение

электробезопасности в быту сельского населения: Дисс. на соиск. учен. степ. канд. техн. наук/ Еремина Тамара Владимировна. - Челябинск, 1989. $-198 \mathrm{c}$.

7. Спирин, Н.А. Методы планирования и обработки результатов инженерного эксперимента/ Н.А. Спирин, В.В. Лавров. - Екатеринбург: Изд-во УГТУ-УПИ, 2003. - $256 \mathrm{c.}$

8. Балашов О.П. Методика планирования экспериментальных исследований токов утечки в электроустановках зданий // Труды Рубцовского индустриального института: Выпуск 21 / Под ред. А.А. Апполонова / Рубцовский индустриальный институт. - Рубцовск, 2013. - 123 с. С.30-35.

УДК 51-74

ГРНТИ 44.35 .31

\title{
МАТЕМАТИЧЕСКАЯ МОДЕЛЬ ВЛИЯНИЯ ПОВЫШЕННЫХ ВИБРАЦИЙ
} НА РАБОТУ ГИДРОАГРЕГАТА

\author{
Бондаренко Наталья Евгеньевна \\ Студент 4 курса \\ филиала ФГБОУ ВО «НИУ «МЭИ» \\ в г. Волжском, Россия \\ Латышов Кирилл Васильевич \\ Студент 4 курса \\ филиала ФГБОУ ВО «НИУ «МЭИ» \\ в г. Волжском, Россия \\ Зенина Елена Геннадвевна \\ кандидат технических наук, \\ дочент кафедры Энергетики \\ филиала ФГБОУ ВО «НИУ «МЭИ» \\ в г. Волжском, Россия
}

\section{АННОТАЦИЯ}

В настоящее время в основном все методы диагностики основаны на наблюдениях в процессе работы или при осмотрах и испытаниях. Но главной проблемой при этом остается отсутствие преждевременного выявления дефектов на стадии развития. Это возможно только благодаря численному моделированию процессов в гидроагрегате, которые бы позволяли оценивать его состояние. Использование модели в АСУТП ГЭС с применением компьютерных технологий сбора и обработки информации обеспечивает непрерывность контроля, достоверность оценок и возможность анализа динамики развития процесса.

Целью работы является анализ исходных данных по контролю вибрации, оценка вибросостояния гидроагрегата и разработка рекомендаций для его дальнейшей эксплуатации, предложение математической модели на основе описания движения ротора. 